\title{
PHYSICIANS' ATTITUDE TOWARDS ARTIFICIAL INTELLIGENCE IN MEDICINE, THEIR EXPECTATIONS AND CONCERNS: AN ONLINE MOBILE SURVEY
}

\author{
Muhammad Alimin Mat Reffien, Ellyana Mohamad Selamat, Hanani Nabilah Mohd Sobri, Mohd \\ Fathulzhafran Mohamed Hanan, Mohd Ihsanuddin Abas, Muhammad Faiz Mohd Ishak, Noor Atika Azit, \\ Noor Dalila Inche Zainal Abidin, Nor Hazmi Noor Hassim, Norain Ahmad, Sharifah Ain Shameera Syed \\ Rusli, Sharifah Fazlinda Syed Nor and Aniza Ismail*
}

Department of Community Health, Faculty of Medicine, Universiti Kebangsaan Malaysia

Corresponding author: Aniza Ismail

Email: aniza@ppukm.ukm.edu.my

\begin{abstract}
The application of artificial intelligence (Al) is on the rise in the healthcare industry. However, the study on the physicians' perspectives is still lacking. The study aimed to examine physicians' attitudes, expectations, and concerns regarding the application of Al in medicine. A cross-sectional study was conducted in October 2019 among physicians in a tertiary teaching hospital in Malaysia. The survey used a validated questionnaire from the literature, which covered: (1) socio-demographic profile; (2) attitude towards the application of Al; (3) expected application in medicine; and (4) possible risks of using Al. Comparison of the mean score between the groups using a t-test or one-way analysis of variance (ANOVA). A total of 112 physicians participated in the study: $64.3 \%$ from the clinical departments; $35.7 \%$ from the non-clinical specialties. The physicians from non-clinical departments had significantly higher mean attitude score (mean $=14.94 \pm 3.12$ ) compared to the clinical (person-oriented) departments (mean $=14.13 \pm 3.10)$ and clinical (technique-oriented) departments (mean $=13.06 \pm 2.88)(p=0.033)$. The tech-savvy participants had a significantly higher mean attitude score (mean $=14.72 \pm 3.55)$ than the non-tech-savvy participants (mean $=13.21 \pm 2.46)(p=0.01)$. There are differences in the expectations among the respondents and some concerns exist especially on the legal aspect of Al application in medicine. Proper training and orientation should precede its implementation and must be appropriate to the physicians' needs for its utilization and sustainability.
\end{abstract}

Keywords: Artificial Intelligence, medicine, physicians' attitude, expectations, concerns

\section{INTRODUCTION}

Moving forward to the $4^{\text {th }}$ Industrial Revolution (4IR), we live with intelligent machines that ease daily chores. Klaus Schwab, Founder and Executive Chairman of the World Economic Forum described the 4IR in 2016 book as a culmination of emerging technologies fusion into the physical and biological worlds the likes of which has not been seen before ${ }^{1}$. Virtual assistants such as Siri, face recognition at passport control counters, and Netflix, a content-on-demand movie hub, are examples of artificial intelligence (Al) developed to fulfil the recent needs and demands. Al offers deep learning of the available data, where digitized input is processed through multiple layers of 'neurons' that detect features, and then produce the output ${ }^{2}$. In medicine, the application of Al consists of two main branches: virtual and physical.

The virtual component is represented by Machine Learning (also known as Deep Learning), comprising of mathematical algorithms that improve learning through experience ${ }^{3}$. For example, the prediction of over 5000 protein complexes is possible with the use of "evolutionary enhanced Markov clustering" ${ }^{4}$. The

more common virtual applications of Al in hospitals are the use of specific algorithms in electronic medical records to identify clients with a family history of a hereditary disease or an augmented risk of chronic diseases ${ }^{3}$. For example, the use of big data analytics has significant potential for identifying novel genotypes and phenotypes in heterogenous CV diseases, such as Brugada syndrome, Takotsubo cardiomyopathy, white-coat hypertension and metabolic syndrome ${ }^{5-6}$. The second component of the application of $\mathrm{Al}$ in medicine takes a more physical form such as tangible objects, medical devices, and increasingly sophisticated robots taking part in the delivery of care (carebots) ${ }^{7}$.

In Malaysia, the use of $\mathrm{Al}$ in the healthcare industry also follows the same trend. Earlier in 2019, the Ministry of Health Malaysia announced the application of Al for predicting outbreaks of infectious diseases such as dengue ${ }^{8}$. This application can signal the early warning sign to alert healthcare providers. Thus, early preparation for outbreaks would help to address the issue of overcrowding and long waiting times at hospitals and clinics. A Malaysian company introduced another advancement in the use of $\mathrm{Al}$ in medicine in the form of smart stethoscope. It is the world's first stethoscope that allows users to listen to a patient's heart and lungs with sophisticated amplification and filtering technology ${ }^{9}$. Besides that, the recordings can be transmitted to a smart device such as a 
smartphone or a tablet via Bluetooth, enabling a build-in personal biometric signature for each patient to detect the presence of heart or lung diseases.

Despite these advances and proven usefulness, physicians' responses towards Al technology remain ambivalent. Even though about 35\% of healthcare organizations plan to adopt Al within 2 years and another half intend to do so within 5 years, only $23.5 \%$ of physicians have indicated that they will use Al within 2 years; another $24.7 \%$ indicate that they would do so in $3-5$ years $^{10}$. Up until mid-2017, only $4.7 \%$ of physicians were already using Al technologies ${ }^{10}$. Similarly, a survey conducted among healthcare leaders in the Middle East revealed that $60 \%$ thought $\mathrm{Al}$ and robotics would have a significant impact on their businesses, although less than $20 \%$ of healthcare leaders were doing anything to promote $\mathrm{Al}$ and robotics use ${ }^{11}$.

However, there remains a lack of studies on physicians' attitudes towards Al in developing countries, especially in Malaysia. Physicians' perception should be viewed with utmost importance because they are the ones who will be adopting Al technologies. Serious problems can arise when, despite demonstrated examples of its beneficial applications for human patients, healthcare professionals remain reluctant to adopt $\mathrm{Al}^{12}$. Early identification of their concerns regarding the adoption of $\mathrm{Al}$ will assist $\mathrm{Al}$ firms in addressing their concerns and improving the adoption rate. It is important to survey physicians' general perceptions towards $\mathrm{Al}$, which may pave the way for further research on the topic. Therefore, the objective of this study is to examine physicians' attitudes, expectations and concerns regarding the application of $\mathrm{Al}$ in healthcare.

\section{METHODS}

\section{Study Setting and Participants}

It is a cross-sectional study that implemented the survey technique. The survey was conducted for one month during October 2019. We surveyed physicians, both clinical and non-clinical, serving at a tertiary university teaching hospital in Kuala Lumpur. The sample size calculation was 100 participants, including a $20 \%$ non-response rate, which was determined using Epi Info software version 7.2.2.6 for population survey with a $95 \%$ confidence level. We used purposive sampling in which representatives from various departments in different positions were selected to ensure diverse variation in both job position and speciality. The survey was administered online using Google Forms. Participants from personal and professional connections received a mobile phone invitation containing a web link to the questionnaire. Prior to participation in the survey, the respondents were informed about the objective of the survey in the preface of the questionnaire, and informed consent was obtained.

\section{Study Instrument}

We used a validated questionnaire for our online survey ${ }^{13}$ after obtaining formal permission via email from the original author. The contents of the online survey consisted of a questionnaire with four parts: (1) demographic profile; (2) attitude towards the application of $\mathrm{Al}$; (3) expected application in medicine; and (4) possible risks of Al use. For the first part of the survey, the questions were related to the general demographic profile, e.g. age, duration of service, sex, ethnicity, job position and department as well as perceived tech-savviness. The second part of the survey involved questions on the physician's attitude toward the medical application of Al. This section had five questions with 5-point Likert scale responses (Item 1-5) and two close-ended questions (Item 6 and 7) with possible answer choices (if applicable). The items that involve the Likert scale responses were: Do you agree that you have good familiarity with Al?, Do you agree that Al has useful applications in the medical field?, Do you agree that the diagnostic ability of $\mathrm{Al}$ is superior to the clinical experience of a human doctor?, Do you agree that Al could replace your job? and Do you agree that you would always use Al when making medical decisions in the future? The two close-ended items were: What are the advantages of using AI? and If your medical judgment and an Al's judgments differ, which will you follow? For the third part of survey (Item 8 and 9), we asked two closed-ended questions to the physicians about the medical fields in which Al could be applied. The items were: In which field of medicine do you think Al will be most useful? and Which sector of healthcare do you think will be the first to commercialize Al? In the last part of the survey (Item 10 and 11), the physicians were asked which problems and possible risks they were concerned about regarding the application of $\mathrm{Al}$ in medicine. The two closed-ended questions with possible answer choices (if applicable) were: What are you concerned about application of Al in medicine?, and Who do you think will be liable for legal problems caused by Al?

We pilot-tested the questionnaire's reliability in a local setting. The pilot testing was conducted by medical doctors $(n=20)$ representative of the target population ${ }^{14}$. The pilot study yielded a Cronbach's alpha of 0.63 , which was deemed satisfactory and acceptable value for reliability ${ }^{15}$.

\section{Ethical Approval}

The study has been approved by the university Medical Research and Ethics Committee.

\section{Data Analysis}

We used Statistical Package for the Social Sciences (SPSS) version 22.0 for the statistical data analysis. For descriptive analyses, 
categorical data were described using frequency and percentages; continuous data were described using the mean and standard deviation. Bivariate analysis was performed using one-way analysis of variance (ANOVA) or the $t$-test. A $p$-value $<0.05$ was considered statistically significant.

\section{RESULTS}

The physicians' socio-demographic characteristics are shown in Table 1 . In total, 112 respondents completed the questionnaire. The mean \pm standard deviation (SD) of the age of the respondents was $33.35 \pm 2.99$ years. Whereas, the mean \pm SD of the duration of practice was $8.08 \pm$ 3.03 years. Most respondents were women (67.9\%), Malay (77.7\%), worked in clinical departments (64.3\%). Besides, the vast majority of the respondents were medical officers $(86.6 \%)$, followed by specialists $(6.3 \%)$, house officers $(5.4 \%)$ and consultants $(1.8 \%)$. Slightly more than half $(57.1 \%)$ considered themselves to be techsavvy.

Physicians' attitude toward Al and its association with socio-demographic characteristics are summarized in Table 2 . The mean \pm SD score on attitude scale was $13.94 \pm 3.14$ (range $=5-25)$. There were significant differences of mean attitude score between departments/specialties $(p=0.033)$ and perception of tech-savviness $(p=0.020)$.

Table 1. Socio-demographic Characteristics of Physicians'

\begin{tabular}{lc}
\hline Characteristics & $\mathbf{N}(\%)$ \\
\hline Age (years) & $14(12.5)$ \\
$\leq 30$ & $64(57.1)$ \\
$31-34$ & $34(30.4)$ \\
$\geq 35$ & \\
Duration of practice (years) & $13(11.6)$ \\
$\leq 5$ & $73(65.2)$ \\
$6-9$ & $26(23.1)$ \\
$\geq 10$ & \\
Gender & $36(32.1)$ \\
Male & $76(67.9)$ \\
Female & \\
& \\
Ethnicity & $87(77.7)$ \\
Malay & $15(13.4)$ \\
Chinese & $8(7.1)$ \\
Indian & $2(1.8)$ \\
Others & \\
Job position & $6(5.4)$ \\
House officer & $97(86.6)$ \\
Medical officer & $7(6.3)$ \\
Specialist & $2(1.8)$ \\
Consultant & \\
Departments/specialties & \\
Non-clinical & \\
Clinical - Surgical-based & \\
Clinical - Medical-based & \\
Tech-savviness & $40(35.7)$ \\
Yes & $33(29.5)$ \\
No & $39(34.8)$ \\
\hline Con & \\
\hline
\end{tabular}

${ }^{a}$ Community health

bSurgery, anaesthesiology, dermatology, emergency medicine, otolaryngology, ophthalmology, pathology, orthopaedic and radiology

'Family medicine, internal medicine, obstetrics \& gynaecology, paediatrics, physical medicine and rehabilitation, palliative care and psychiatry 
Table 2. Association Between Respondents' Socio-Demographic Characteristics and Physicians' Attitude Score

\begin{tabular}{|c|c|c|c|}
\hline \multirow[t]{2}{*}{ Characteristics } & \multicolumn{2}{|c|}{ Physicians' Attitude Score } & \multirow[b]{2}{*}{ P-value } \\
\hline & Mean score (SD) & Test & \\
\hline \multicolumn{4}{|l|}{ Age (years) } \\
\hline$\leq 30$ & $15.64(3.46)$ & $F=2.429$ & 0.093 \\
\hline $31-34$ & $13.66(3.27)$ & & \\
\hline$\geq 35$ & $13.76(2.58)$ & & \\
\hline \multicolumn{4}{|l|}{ Duration of practice (years) } \\
\hline$\leq 5$ & $15.00(3.46)$ & $F=1.692$ & 0.189 \\
\hline $6-9$ & $13.88(3.28)$ & & \\
\hline$\geq 10$ & $13.58(2.52)$ & & \\
\hline \multicolumn{4}{|l|}{ Gender } \\
\hline Male & $14.56(3.81)$ & $t=1.562$ & 0.153 \\
\hline Female & $13.64(2.75)$ & & \\
\hline \multicolumn{4}{|l|}{ Ethnicity } \\
\hline Malay & $13.95(3.11)$ & $t=0.669$ & 0.918 \\
\hline Non-Malay & $13.88(3.33)$ & & \\
\hline \multicolumn{4}{|l|}{ Job position } \\
\hline House officer & $16.83(1.83)$ & $F=1.364$ & 0.251 \\
\hline Medical officer & $13.78(3.23)$ & & \\
\hline Specialist & $13.57(1.62)$ & & \\
\hline Consultant & $14.00(2.83)$ & & \\
\hline \multicolumn{4}{|l|}{ Departments/specialties } \\
\hline Non-clinical & $14.94(3.12)$ & $F=3.517$ & 0.033 \\
\hline Clinical - Surgical-based & $14.13(3.10)$ & & \\
\hline Clinical - Medical-based & $13.06(2.88)$ & & \\
\hline \multicolumn{4}{|l|}{ Tech-savviness } \\
\hline Yes & $14.53(3.48)$ & $t=2.525$ & 0.020 \\
\hline No & $13.15(2.44)$ & & \\
\hline
\end{tabular}

The respondents' responses regarding the advantages of Al use in medicine are described in table 3. The majority of the respondents agreed that Al could speed up processes in healthcare, can deliver amounts of clinically relevant highquality data and has no emotional exhaustion nor physical limitation. However, when we surveyed the respondents on whether the doctor or Al's opinion should be followed if there was a difference in medical judgement, most (81.74\%) would follow the doctor's opinion as compared to that of the $\mathrm{Al}$ (18.26\%). The respondents' expectations regarding the different areas of $\mathrm{Al}$ use in medicine and first healthcare sector to commercialize $\mathrm{Al}$ are shown in Figure 1 and Figure 2 respectively. While the responses regarding the respondents' concerns about the application of $\mathrm{Al}$ in medicine are shown in Figure 3. When asked on who will be liable for legal problems caused by Al, almost $50 \%$ voted for doctor in-charge, followed by company that created $\mathrm{Al}(34.7 \%)$ and patient who agreed to follow Al's input (15.6\%).

Table 3. Description of respondents' responses regarding the advantages of Al use in medicine

\begin{tabular}{lc}
\hline Advantages of Al use in medicine & Percentage agreed (\%) \\
\hline 1. Al can speed up processes in healthcare & 78.3 \\
2. Al can deliver vast amounts of clinically relevant high-quality data & 46.1 \\
in real time & \\
3. Al can help reduce medical errors & 60.9 \\
4. Al has no emotional exhaustion nor physical limitation & 68.7 \\
5. Al has no space-time constraint & 42.6 \\
\hline
\end{tabular}




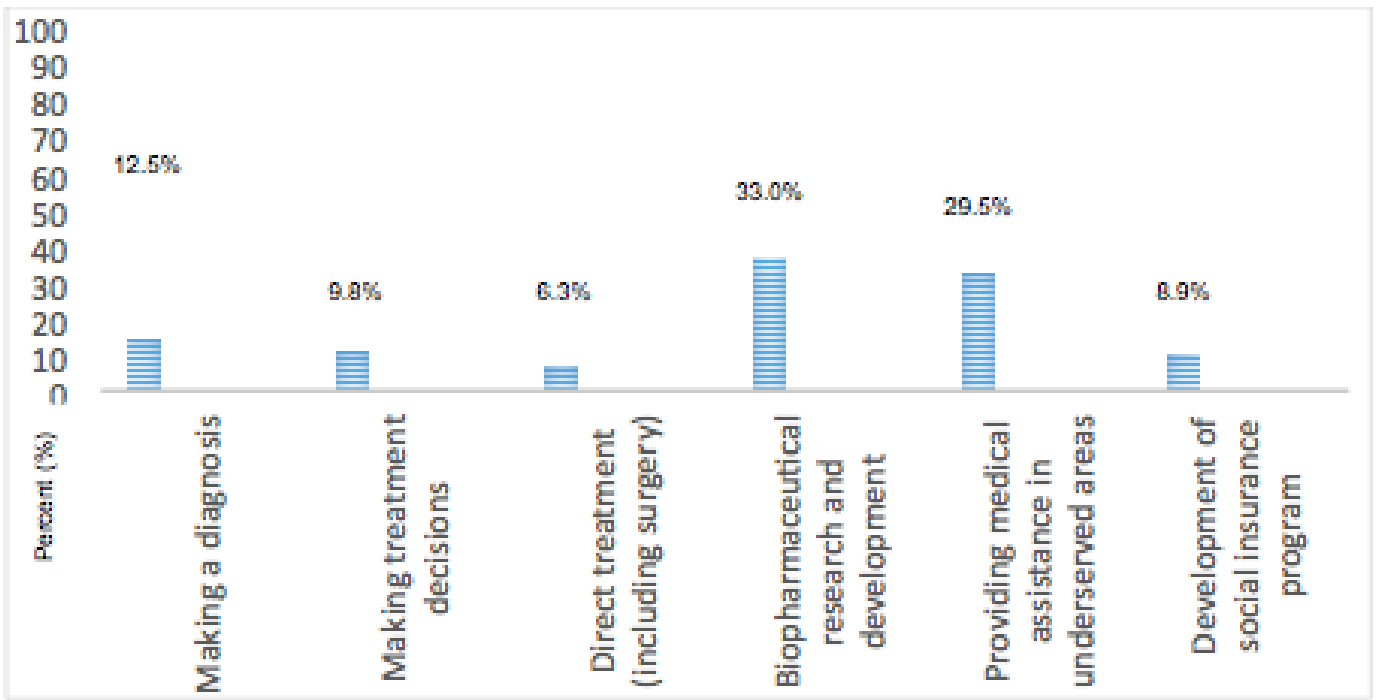

Figure 1. Responses of respondents regarding the different areas of Al usage in medicine

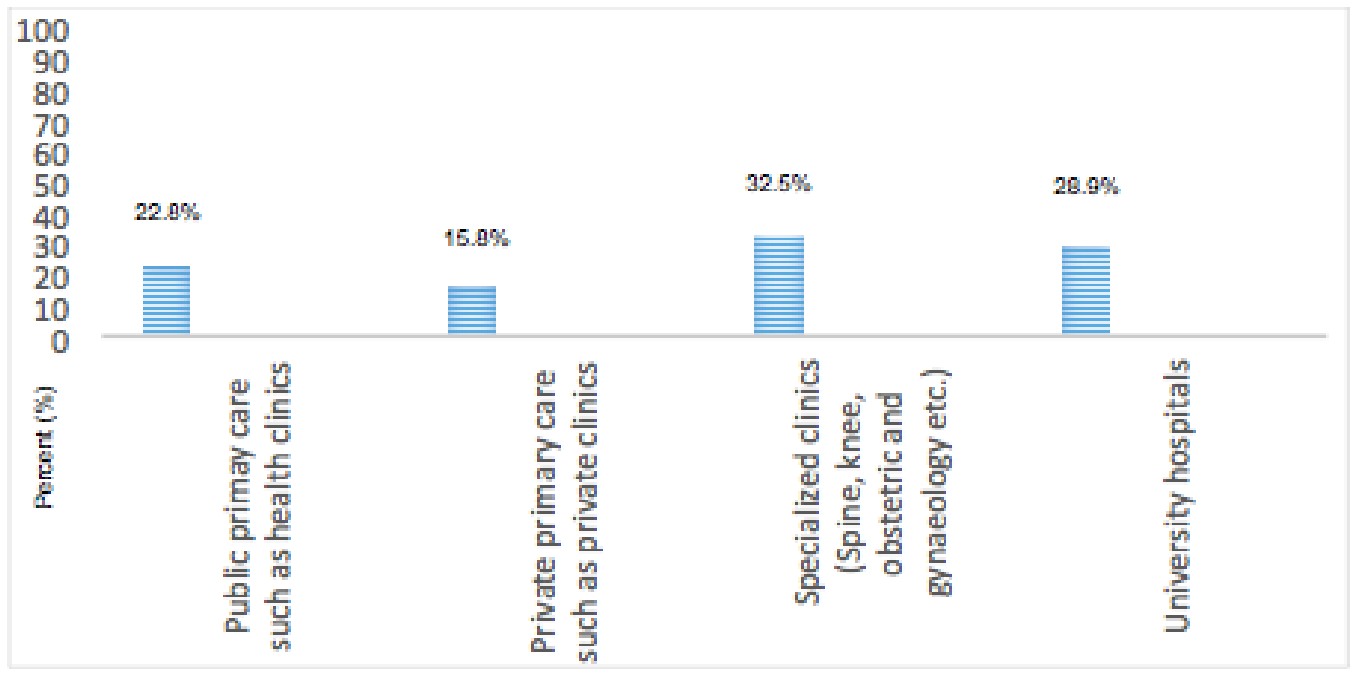

Figure 2. Responses of respondents regarding which sector of health care will be the first to commercialize Al

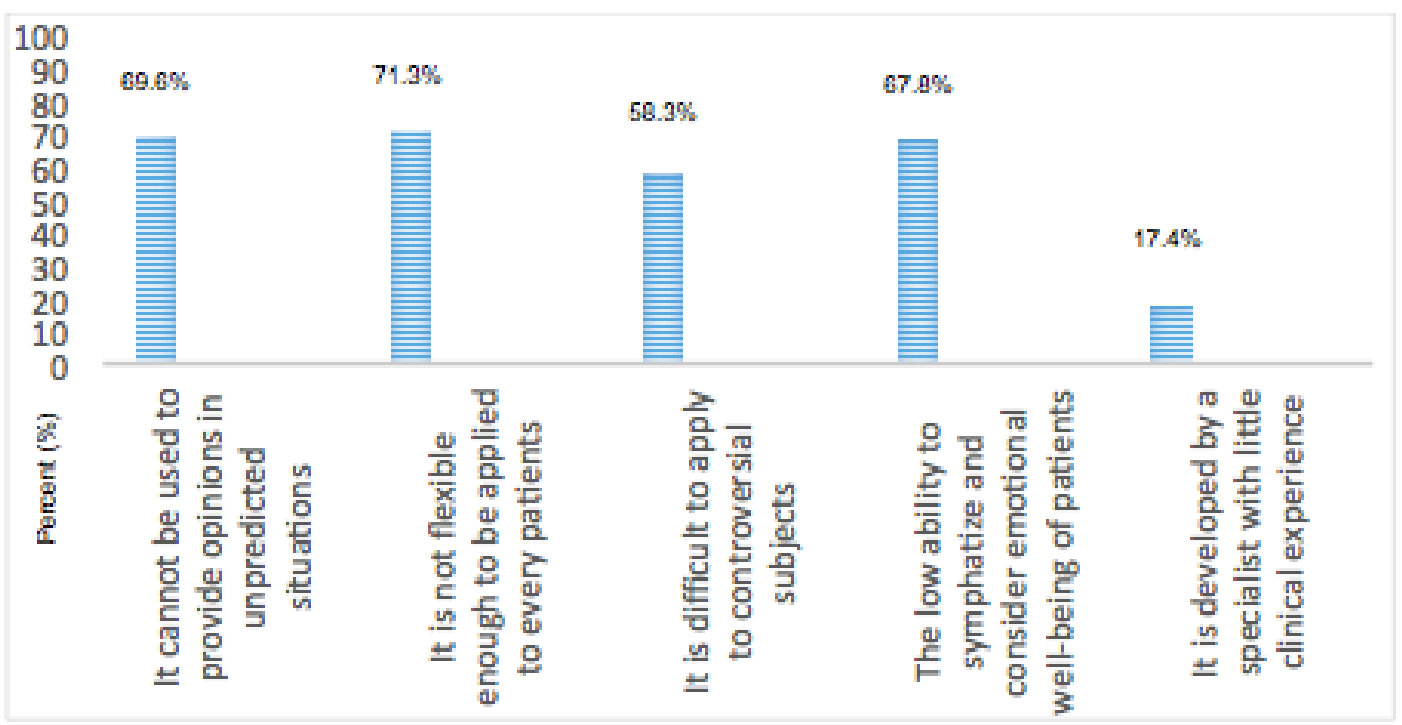

Figure 3. Responses of respondents regarding concerns about application of $\mathrm{Al}$ in medicine 


\section{DISCUSSION}

Artificial intelligence as well as digital technologies and machine learning, are increasingly paving the way to the future, especially in improvising and revolutionizing modern medicine. According to the Future Health Index 2019 by the Dutch firm Royal Philips, China has, at $60 \%$, topped the share of the world's investment and financing in $\mathrm{Al}$ in healthcare from 2013 to 2018, followed by the United States and India at $29 \%$ and $5 \%$, respectively ${ }^{16}$. This development has allowed China to experience more of the benefits of Al over the years. However, despite the abundant opportunities and benefits promised by Al, concerns regarding the ethical, legal and social aspects remain unresolved.

It is undeniable that Al has its pros and cons based on the attitude of the healthcare personnel, which matter the most in moving forward. Some will view Al as a part of the digital transformation of healthcare and will act as clinical extenders and help simplify the medical process, while others will think that it will damage the medical field such by disrupting the physician's role or that of other healthcare staff ${ }^{17}$. Exactly how Al development will be beneficial, especially in the low- and middle-income countries, including Malaysia, has not been fully explored or explained ${ }^{18}$.

In the present study, we found that tech-savvy physicians had better attitudes towards Al compared to the non-tech-savvy physicians. The tech-savvy and non-tech-savvy status was selfproclaimed by the respondents, which reflected their familiarity with the usage of current new technologies, e.g. computers, smart phones and machines. Therefore, those who are well-versed in technology would obviously hold the view that Al will make human life easier and faster. Even though, various studies have identified that older persons are often less literate in interacting with modern information and communication technology, for example computers ${ }^{19}$, mobile phones and tablets ${ }^{20}$, or even using ticket vendor machines $^{21}$. Our study showed that there was no significant difference between age groups and attitude scores.

In terms of different departments or specialties, non-clinical physicians such as public health physicians and clinical administrators had better attitudes regarding Al. These are physicians working in the mostly digitalized area of management, research and education whereby their daily routine work with computers and database analysis. For example, the use of Big Data to demonstrate the spread of epidemics. Tracking online queries on disease symptoms using social media such as Google Search and Twitter can detect signs of imminent outbreaks ${ }^{22-}$ ${ }^{23}$. Thus, due to their exposure, they are more comfortable with the implementation of $\mathrm{Al}$ compared to the clinicians.

On the other hand, the clinician's main task is treating a patient based on disease history, complaint and clinical judgement. In this area, the role of $\mathrm{Al}$ in this task quite unclear and debatable, although studies across multiple medical specialties have applied Al to imitate the diagnostic abilities of physicians ${ }^{24-27}$. A survey among psychiatrists found that this group of clinicians perceived the existence of $\mathrm{Al}$ in their field negatively, especially in replacing their role in managing patients ${ }^{28}$. Our study had shown that most of the clinicians preferred doctor's opinions $(82 \%)$ over Al opinions in making clinical judgement. Thus, we can conclude that the confidence in Al in aiding their clinical decisionmaking is still low. Perhaps this is due to the lack of tests of Al reliability in making real-time diagnosis, as for now, it has only been proven to help in diagnosis based on investigations rather than patient history and clinical presentation.

Nevertheless, the majority of the respondents had positive expectations for $\mathrm{Al}$ in assisting clinicians in medicine practice. This finding was in agreement with other studies showing that Al has been successfully applied in image analysis in radiology, pathology and dermatology units, thus helping in making diagnoses and in reducing medical errors ${ }^{17}$. They believe that machine learning algorithms in clinical practice, which is one of the advantages of $\mathrm{Al}$, will have a positive impact by reducing unwarranted variations, improving efficiency and preventing avoidable medical errors ${ }^{29}$. These advantages can be possible by extracting clinically relevant information and diagnostic evaluation from the high volume of data from EHRs ${ }^{30}$. Some of the advanced features Al can provide real-time risk score; predicting inpatient mortality and morbidity, risk of readmission, prolonged length of stay and discharge outcomes ${ }^{31}$. Perhaps clinicians would be more eager to test the ability of $\mathrm{Al}$ in their practices once the system has been enhanced.

Despite the low acceptance of the capability of Al in medical practice, physicians are still expecting commercialization of $\mathrm{Al}$ in specialist clinics, university hospitals and primary care practices. The choice is perhaps due to the availability of big data in EHRs such as imaging, laboratory results and clinical records that will aid the research and development of healthcare management. Through Al, physicians can now detect novel signals from extracted data, such as novel predictive features for breast cancer prognosis based on stromal cells, cardiovascular risk factor predictions from fundus photography, cardiac blood flow insufficiency from computed topography of the heart and predictors of dementia through retinal imaging ${ }^{17}$. 
Physicians' concerns about the reliability of Al in medical practice are apparent, as the majority still believe that Al cannot provide opinions if it has inadequate clinical information relevant to the specific patient. Patients inevitably have different situations, social backgrounds and emotional states that $\mathrm{Al}$ would be unable to appreciate unless that information is entered into the system. Thus, they are concerned that Al cannot express sympathy towards patients and respond to controversial issues while managing them. These deficiencies would impair the decision-making process tailored to the specific needs of the patients. In this regard, physicians would be the best people to operate and use $\mathrm{Al}$ in decision-making. Perhaps for the time being, Al should just support doctors and not replace them, as Stephen Hawking had mentioned once that machines still lack human qualities, hence humans cannot immediately trust $\mathrm{Al}^{32}$.

As with other new technologies in medical practice, the application of $\mathrm{Al}$ in the medical setting should also take into consideration the ethical and legal impacts. There should be a clear guideline for physicians or healthcare technicians for operating the $\mathrm{Al}$ in managing diseases or patients in clinical settings so that the ethics of medicine, i.e. beneficent and non-maleficent, are observed. Furthermore, this would help define the role and responsibility of humans in machineoperating practices so that the capability and reliability of $\mathrm{Al}$ can be enhanced for the benefit of humankind in the present and the future.

Strength and Limitations To our knowledge, this is the first survey to provide basic information on physicians' expectations and attitudes towards Al in Malaysia. As Al is still new here, conducting such an investigation would provide a foundation for further studies in this field. This study has several limitations. First, we used purposive sampling, which is subject to selection bias, but we were able to include all job positions and fields of practice. Further, the teaching hospital selected for the study might yield different results compared to other non-teaching hospitals. Second, we did not include questions regarding background knowledge of Al. This baseline knowledge may have affected the respondents' attitudes, as they may have different understandings of the application of $\mathrm{Al}$ in healthcare. Third, we used a validated questionnaire adapted from a Korean study, which was developed by doctors rather than Al experts. Thus, our study only provides superficial information regarding physicians' understanding of Al.

\section{CONCLUSION}

We found that most of the respondents generally had a favorable attitude towards the application of $\mathrm{Al}$ in the medical field. They expected that $\mathrm{Al}$ would be implemented mostly in research and development, and commercialization would mostly be in specialized clinics such as obstetrics and gynaecology, spine etc. However, they had concerns regarding the ability of Al to manage patients on an individual basis, predicting unexpected situations with inadequate information and managing human emotions. Nonetheless, the doctor's opinion is superior to the ability of Al in some specific circumstances. We recommend conducting a larger-scale survey to obtain a better view on physicians' attitudes and expectations regarding $\mathrm{Al}$ in Malaysia, and further study is needed to explore the issues and challenges regarding Al in Malaysian healthcare.

\section{Conflict of interest}

The authors declare no potential conflict of interest.

\section{Acknowledgements}

The authors would like to express appreciation to the Hospital Canselor Tuanku Muhriz, Kuala Lumpur, Malaysia, for research support and all the staff who participated In the study. Also, to the Department of Community Health for their support.

\section{REFERENCES}

1. Klaus Schwab. The Fourth Industrial Revolution. World Economic Forum. 2016.

2. Topol EJ. High-Performance Medicine: The Convergence of Human and Artificial Intelligence. Nature medicine. 2019;25(1): 44-56. doi: https: / /doi.org/10.1038/s41591-0180300-7

3. Hamet $P$, Tremblay J. Artificial intelligence in medicine. Metabolism. 2017 Apr 1;69:S36-40. doi: https://doi.org/10.1016/j.metabol.201 7.01.011

4. Theofilatos K, Pavlopoulou N, Papasavvas C, et al. Predicting protein complexes from weighted proteinprotein interaction graphs with a novel unsupervised methodology: evolutionary enhanced Markov clustering. Artificial intelligence in medicine. 2015 Mar 1;63(3):181-9.

doi: https://doi.org/10.1016/j.artmed.2014 .12 .012

5. Krittanawong $\mathrm{C}$, Zhang $\mathrm{H}$, Wang $\mathrm{Z}$, Aydar $M$, Kitai T. Artificial intelligence in precision cardiovascular medicine. Journal of the American College of Cardiology. 2017 May 22;69(21):265764. 
6. Krittanawong $C$. The rise of artificial intelligence and the uncertain future for physicians. European journal of internal medicine. 2018; 48: e13-e14. doi: https://doi.org/10.1016/j.ejim.2017.0 6.017

7. Cornet G. Robot companions and ethics: A pragmatic approach of ethical design. Journal international de bioéthique. 2013;24(4):49-58. doi: https://doi.org/10.3917/jib.243.0049

8. Health Ministry Plans to Use Artificial Intelligence. The Star. March 13, 2019. https: / /www.thestar.com.my/news/na tion/2019/03/13/health-ministry-plansto-use-artificialintelligence\#CR3iDwxx1R0gLbtp. 99. Accessed November 29, 2019.

9. Kamal B. A.I. can help improve patient outcomes. New Strait Times. November 17 , 2018. https: / /www.nst.com.my/opinion/colu mnists/2018/11/432065/ai-can-helpimprove-patient-outcomes. Accessed November 28, 2019.

10. Sullivan T. Half of hospitals to adopt artificial intelligence within 5 years. Healthcare IT News. April 11, 2017. https: //www.healthcareitnews.com/ne ws/half-hospitals-adopt-artificialintelligence-within-5-years. Accessed on November 28, 2019.

11. Clark $\mathrm{H}$. The roadmap to introducing $\mathrm{Al}$ and robotics in healthcare. Forbes Middle East. April 18, 2018. https: / /www.forbesmiddleeast.com/fe atured/special-editions/the-roadmapto-introducing-ai-and-robotics-inhealthcare. Accessed on November 28, 2019.

12. Chui M, Bughin J, Hazan E, et al. Artificial intelligence the next digital frontier? McKinsey Global Institute; 2017.

13. Oh S, Kim JH, Choi SW, et al. Physician Confidence in Artificial Intelligence: An Online Mobile Survey. Journal of medical Internet research. 2019; 21(3): e12422. doi: https: / /doi.org/10.2196/12422.

14. Birkett MA, Day SJ. Internal Pilot Studies for Estimating Sample Size. Statistics in medicine. 1994; 13(23-24): 2455-2463. doi:

https: / /doi.org/10.1002/sim.47801323 09
15. Taber KS. The Use of Cronbach's Alpha When Developing and Reporting Research Instruments in Science Education. Research in Science Education. 2018; 48(6): 1273-1296. doi: https: / /doi.org/10.1007/s11165-0169602-2

16. Future Health Index. 2019. Transforming Healthcare Experiences - Exploring the Impact of Digital Health Technology on Healthcare Professionals and Patients. http:/ / www.indiaenvironmentportal.or g.in/files/file/Future_Health_Index_20 19.pdf. Accessed on November 28, 2019].

17. Miller DD, Brown EW. Artificial Intelligence in Medical Practice: The Question to the Answer? Am J Med. 2018;Feb;131(2):129-133. doi: 10.1016/j.amjmed.2017.10.035.

18. World Health Organization. 2018. Global Health Ethics - Big Data and Artificial Intelligence.

https://www.who.int/ethics/topics/big -data-artificial-intelligence/en/ Accessed on November 28, 2019.

19. Okonji PE. Use of computer assistive technologies by older people with sight impairment: Perceived state of access and considerations for adoption. British Journal of Visual Impairment. 2018;May;36(2):128-42. doi: https://doi.org/10.1177/026461961775 2760

20. Enwald $H$, Kangas $M$, Keränen $N$, Korpelainen R, Huvila I, Jämsä T. Opinions and use of mobile information technology among older people in northern finland-preliminary results of a population based study. Proceedings of the Association for Information Science and Technology. 2016;53(1):1-5. doi: https: //doi.org/10.1002/pra2.2016.145 05301119

21. Schreder G, Smuc M, Siebenhandl K, Mayr E. Age and Computer Self-Efficacy in the Use of Digital Technologies: An Investigation of Prototypes for Public Self-Service Terminals. Proceedings of the Universal Access in HumanComputer Interaction. User and Context Diversity, LNCS. 2018; Volume 8010, pages 221- 230. Springer Berlin Heidelberg, Germany.

22. Deiner MS, Lietman TM, Porco TC. Uncertainties in Big Data When Using Internet Surveillance Tools and Social Media for Determining Patterns in 
Disease Incidence-Reply. JAMA ophthalmology. 2017 Apr 1;135(4):4023. doi: 10.1001/jamaophthalmol.2017.0140

23. Benke KK. Uncertainties in big data when using Internet surveillance tools and social media for determining patterns in disease incidence. JAMA ophthalmology. $2017 \quad$ Apr 1;135(4):402.doi:

doi:10.1001/jamaophthalmol.2017.0138

24. Gulshan V, Peng L, Coram M, et al. Development and Validation of a Deep Learning Algorithm for Detection of Diabetic Retinopathy in Retinal Fundus Photographs. JAMA. 2016;316(22):24022410. doi:10.1001/jama.2016.17216

25. Kermany DS, Goldbaum M, Cai W, et al. Identifying medical diagnoses and treatable diseases by image-based deep learning. Cell. 2018 Feb 22;172(5):112231. doi: https: / /doi.org/10.1016/j.cell.2018.02 .010

26. Esteva A, Kuprel B, Novoa RA, Ko J, Swetter SM, Blau HM, Thrun S. Dermatologist-level classification of skin cancer with deep neural networks. Nature. 2017 Feb;542(7639):115-8. doi: https://doi.org/10.1038/nature21056

27. Cheng JZ, Ni D, Chou YH, Qin J, Tiu CM, Chang YC, Huang CS, Shen D, Chen CM. Computer-aided diagnosis with deep learning architecture: applications to breast lesions in US images and pulmonary nodules in CT scans. Scientific reports. 2016 Apr 15;6(1):13.doi:

https: / /doi.org/10.1038/srep24454

28. Doraiswamy PM, Blease C, Bodner K.
Artificial intelligence and the future of psychiatry: Insights from a global physician survey. Artificial Intelligence in Medicine. 2020 Jan 1;102:101753.3. doi:

https: / /doi.org/10.1016/j.artmed.2019 .101753

29. Kelly CJ, Karthikesalingam A, Suleyman $M$, Corrado G, King D. Key challenges for delivering clinical impact with artificial intelligence. BMC Medicine. 2019 17:195. doi: https: / / doi.org/10.1186/s12916-0191426-2

30. Liang $\mathrm{H}$, Tsui BY, $\mathrm{Ni} \mathrm{H}$, Valentim $\mathrm{CC}$, Baxter SL, Liu G, Cai W, Kermany DS, Sun $X$, Chen J, He L. Evaluation and accurate diagnoses of pediatric diseases using artificial intelligence. Nature medicine. 2019 Mar;25(3):433-8. doi: https: / / doi.org/10.1038/s41591-0180335-9

31. Rajkomar A, Oren E, Chen K, Dai AM, Hajaj N, Hardt $M$, et al. Scalable and accurate deep learning with electronic health records. NPJ Digit Med. 2018; $1: 18$. doi: https: / / doi.org/10.1038/s41746-0180029-1.

32. Stephen Hawking. Artificial intelligence could be the greatest disaster in human history. Independent. October 2016. https://www.independent.co.uk/news /people/stephen-hawking-artificialintelligence-diaster-human-historyleverhulme-centre-cambridgea7371106.html. Accessed November 28, 2019. 